\title{
Long-term seasonality of rainfall in the southwest Florida Gulf coastal zone
}

\author{
Margaret Gitau ${ }^{1, *}$ \\ ${ }^{1}$ Agricultural and Biological Engineering, Purdue University, 225 South University Street, West Lafayette, IN 47907, USA
}

\begin{abstract}
In addition to supporting fisheries and wildlife, coastal water resources provide a variety of ecosystem services including water purification and storm surge protection, and the intangible such as educational, spiritual, and inspirational benefits. The integrity of these resources is, however, threatened by the inherent impacts of climate variability and change. Seasonality of climate is particularly important as it influences ecosystem diversity and other sensitive ecosystem components that are important to water resource integrity. For example, rainfall seasonality affects water availability, timing of inputs, seasonal water balance, ecological responses, and inter-annual responses of water resource systems. This study examines long-term seasonality of rainfall in the coastal zone with particular focus on the southwest Florida Gulf coastal zone. Analyses show marked inter-annual variations in rainfall seasonality, although trends are not significant. Decadal patterns show a primarily seasonal regime $(0.6 \leq$ Decadal Seasonality Index $\leq$ 0.79 ) with one markedly wet season and 2 drier periods. A cyclic pattern in seasonality is discernible on a regional basis, although there seems to have been a shift in cycle spans from $20 \mathrm{yr}$ in the earlier decades to $30 \mathrm{yr}$ in more recent decades, which could render water resource systems more vulnerable to climate change effects. The analyses showed a tendency towards long drier periods along with increases in rainy season (June-September) rainfall and progressive decreases in October-December rainfall. Results provide information useful for management decision-making and a basis for further assessments in the region. Approaches and methodologies are applicable to other coastal areas.
\end{abstract}

KEY WORDS: Water resources $\cdot$ Coastal zone $\cdot$ Climate $\cdot$ Seasonality $\cdot$ Rainfall

\section{INTRODUCTION}

In addition to oceans and upwelling areas, coastal water resources comprise a complex combination of estuaries, coastal wetlands, seagrass meadows, bays, gulfs, lagoons and/or sounds, among other features. Estuaries are particularly important in that they provide a mixing zone for freshwater emanating from upstream areas and saltwater tidal influxes. This mixing creates a transitional zone between land and sea that is a diverse and rich ecosystem comprising a unique composition of flora and fauna (US Environmental Protection Agency 2012, Wilson \& Farber undated). Coastal water resources provide a variety of ecosystem services including water purification and

${ }^{*}$ Corresponding author: mgitau@purdue.edu storm surge protection, and the impalpable such as spiritual and inspirational benefits (US Commission on Ocean Policy 2004, US Environmental Protection Agency 2012, Wilson \& Farber undated), in addition to supporting fisheries and wildlife. These resources are currently threatened by a variety of factors including: population growth, rapid urbanization, hydromodification, loss of water to upstream (primarily) agricultural abstraction, water quality impairment, and energy development (US Commission on Ocean Policy 2004, Gill 2005, US Environmental Protection Agency 2012, Wong et al. 2014, Wilson \& Farber undated). These impacts are further exacerbated by the inherent impacts of climate variability and change.

() The author 2016. Open Access under Creative Commons by Attribution Licence. Use, distribution and reproduction are unrestricted. Authors and original publication must be credited. 
Climate is in itself an important factor in working towards sustainable development and management of coastal water resources. Seasonality of climate is particularly important as it influences ecosystem diversity and other sensitive ecosystem components (Feng et al. 2013). In particular, rainfall seasonality affects water availability, timing of (both direct and indirect) inputs, seasonal water balance, ecological responses, and inter-annual responses of water resource systems (Tedesco et al. 2008, Feng et al. 2013, Berghuijs et al. 2014). Rainfall seasonality has also been found to play a very important role in watershed classifications (Coopersmith et al. 2012).

Walsh \& Lawler (1981) designed an index to assess rainfall seasonality. The index was designed to be a simple and yet effective way to get around the limitation of assessments based on basic analysis of monthly rainfall distributions. Coopersmith et al. (2012) formulated an index derived from the Walsh \& Lawler (1981) index. This adaptation was designed to accommodate daily precipitation and was used as part of a suite of measures aimed at characterizing hydrologic similarity of watersheds. Feng et al. (2013) presented an alternate index relating normalized mean monthly

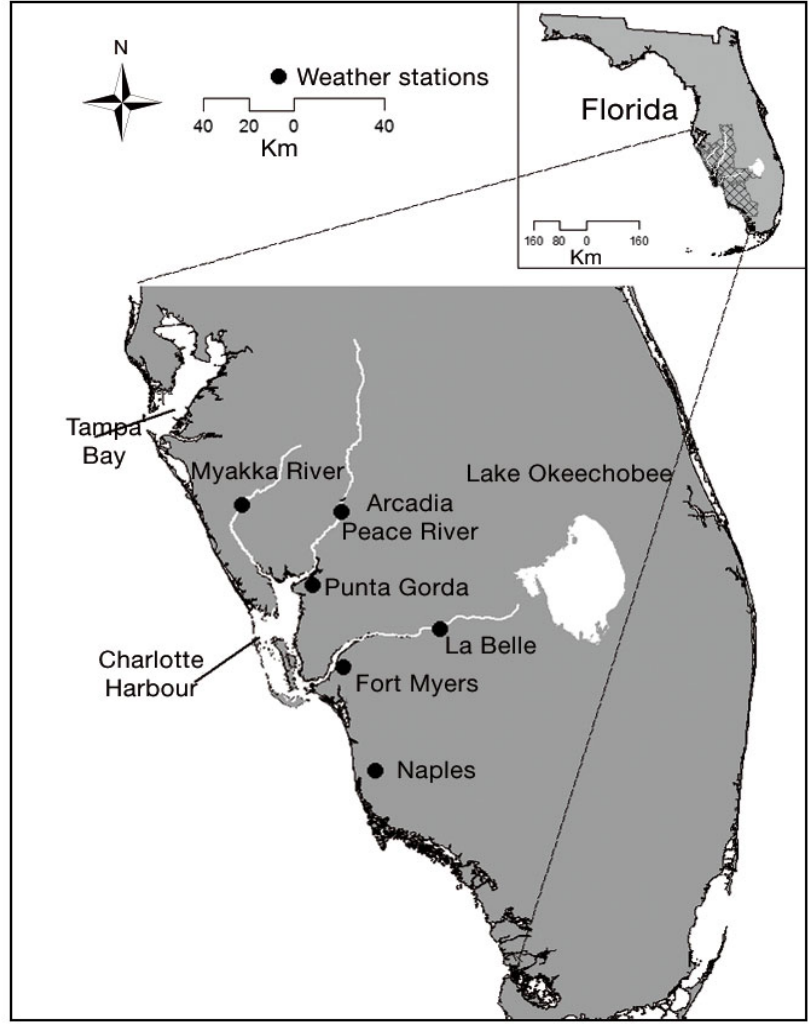

Fig. 1. Southwest Florida region showing weather station locations. Cross-hatching: southwest Florida Gulf coastal region. Rivers from northwest to southeast: Mykka River, Peace River, and Caloosahatchee River rainfall with rainfall entropy, with the intent being to formulate a global measure of seasonality that captured both magnitude and concentration of rainy seasons. Both the Walsh \& Lawler (1981) and Coopersmith et al. (2012) indices have associated interpretive codes for use with the indices, with the former being more detailed and descriptive. The Walsh \& Lawler (1981) index is the more commonly used index, with applications primarily relating to spatial comparisons and analysis of long-term variability and trends in precipitation (e.g. Sumner et al. 2001, Kanellopoulou 2002, Hu et al. 2003, Livada \& Asimakopoulos 2005, Celleri et al. 2007, Guhathakurta \& Saji 2013). This index can also be applied to other climatological and hydrologic components (Walsh \& Lawler 1981).

The present study examines rainfall seasonality in the coastal zone with particular focus on the southwest Florida Gulf coastal zone. Specifically, this study determined long-term seasonality of rainfall with a view to identifying existing trends for various stations and across the region. Results provide information that is useful for management decision-making while also providing a basis for further assessments in the region. Approaches and methodologies are applicable to other coastal areas.

\section{MATERIALS AND METHODS}

\subsection{General description}

As defined for this study, the southwest Florida Gulf coastal region (Fig. 1) comprises the region between the Florida Keys and Tampa Bay, covering the region west of Lake Okeechobee. In just over 100 years, this once expansive wetland has been transformed into a region characterized by agriculture, industry, and residential development (Charlotte Harbor National Estuary Program 2010), this being largely associated with population growth in the region (Obeysekera et al. 1999). Rainfall occurs throughout the year, although the region experiences distinct wetter and drier periods. The mean annual precipitation in the region ranges between $1320 \mathrm{~mm}$ (52 in) and $1420 \mathrm{~mm}$ (56 in) based on 1981-2010 climate normals for Arcadia, Fort Myers, and Naples (Fig. 1) as obtained from the Florida Climate Center (http://climatecenter.fsu. edu/products-services/data). Also characteristic of the region are tropical storms and hurricanes, which typically occur about once a year and once in $10 \mathrm{yr}$, respectively, and usually in August through October (Obeysekera et al. 1999). Notably, the region was impacted either directly or indirectly by major hurricanes 
in 1926 (Great Miami), 1928 (San Fellpe-Okeechobee), 1935 (FL Keys Labor Day), 1960 (Donna), 1992 (Andrew), 1998 (Mitch - as tropical storm), 2004 (Charley, Frances, Ivan, Jeanne - as tropical storm), and 2005 (Katrina - as tropical storm, Wilma) (NOAA undated). Temperatures are generally mild, with mean daily temperatures ranging between $15.6^{\circ} \mathrm{C}\left(60^{\circ} \mathrm{F}\right.$, January) and $28.9^{\circ} \mathrm{C}\left(84^{\circ} \mathrm{F}\right.$, August), and maximum temperatures ranging between $22.8^{\circ} \mathrm{C}\left(73^{\circ} \mathrm{F}\right.$, January) and $33.9^{\circ} \mathrm{C}\left(93^{\circ} \mathrm{F}\right.$, July). Hence, seasons in the region are generally related to precipitation rather than temperatures (Obeysekera et al. 1999). The region has long periods of precipitation data ranging from $50 \mathrm{yr}$ at Punta Gorda to 123 yr at Fort Myers (Fig. 1). These data were used in the analyses as described in ensuing subsections.

\subsection{Rainfall data preprocessing}

Raw rainfall data were obtained through the Florida Climate Center using the center's Downloadable Data Tool (http://climatecenter.fsu.edu/climatedata-access-tools/downloadable-data). This tool allows users to access data from National Weather Service first order and cooperative stations as well as Federal Aviation Administration stations. For each of the stations, all available daily precipitation data were preprocessed to prepare them for analyses. The data were assigned decadal designations (1900s, 1950 s, 2000s, etc.) based on year. The decades were further assigned the numbers 0 (1890s) to 12 (2010s) for ease of analyses and cross-reference among datasets. The 2010s were not included in the main analyses; rather, the data were used for comparison purposes and to provide indications of current directions relative to historical trends.

As a starting point, total precipitation for each station was computed on a monthly and annual basis. For analyses, months with missing data were excluded, consistent with Lana et al. (2004). For example, monthly totals were only preserved for months that had no missing values and annual totals were only preserved for years in which all 12 months had a full set of data. The remaining data constituted a sizeable dataset with monthly data ranging from $50 \mathrm{yr}$ at Punta Gorda to 113 yr at Fort Myers, and annual data from 26 yr at La Belle to 84 yr at Fort Myers. Data preserved for decadal analysis were determined considering the extent of completeness in the monthly datasets; because there are $10 \mathrm{yr}$ in each decade, a complete set for any one month in the decade would have 10 entries (10 Jan, $10 \mathrm{Feb}$, etc.), these being years for which the specific month had complete data (30 or $31 \mathrm{~d}$ as appropriate, 28 or 29 for February). Generally, there were at least 7 entries for each month in each decade (that is, available data for the specific month were complete in at least 7 of the years within the decade) with the exception of La Belle, which had very few data for the 1920s and the 1990s and beyond. Thus, for this station, most of the analyses were carried out for the 1930s to 1980s. Both Arcadia and Fort Myers had some data from the late 1890s; however, these data were largely incomplete, and this decade (1890s) was thus excluded from all analyses. All other available data were used in the analyses.

As part of the preprocessing, initial analysis was conducted on annual rainfall to establish trends in the data on both an annual and a decadal basis. This was done to provide a comparison with subsequent analyses of seasonal trends.

\subsection{Rainfall seasonality analyses}

For seasonality analyses, this study used the Walsh \& Lawler (1981) seasonality index:

$$
\overline{\mathrm{SI}}=\frac{1}{\bar{P}} \sum_{n=1}^{12}\left|\bar{P}_{n}-\frac{\bar{P}}{12}\right|
$$

where $\bar{P}$ is the average annual precipitation for the study period and $\bar{P}_{n}$ is the mean monthly precipitation for month $n$ over the same period. This index was selected as it is simple and it has been used successfully and reliably in several previous applications (e.g. Sumner et al. 2001, Kanellopoulou 2002, Hu et al. 2003, Celleri et al. 2007, Guhathakurta \& Saji 2013).

For this study, an individual year seasonality index $\left(\mathrm{SI}_{a}\right)$ was first calculated for each year of data for each station:

$$
\mathrm{SI}_{\mathrm{a}}=\frac{1}{P_{\mathrm{a}}} \sum_{n=1}^{12}\left|P_{n}-\frac{P_{\mathrm{a}}}{12}\right|
$$

where $P_{\mathrm{a}}$ is the total annual precipitation for each year and $P_{n}$ is the total monthly precipitation for month $n$. $\mathrm{SI}_{\mathrm{a}}$ is only computed for years with complete datasets. The resulting seasonality values were then averaged across the decades (Eq. 3) to provide an indication of decadal seasonality:

$$
\overline{\mathrm{SI}}_{\mathrm{a}}=\frac{1}{N} \sum_{i=1}^{N}\left(\mathrm{SI}_{\mathrm{a}}\right)_{i}
$$

where $N$ is the total number of years with complete (12 month) datasets in the decade. This was done so as not to lose important variability information through smoothing of the data (Sumner et al. 2001), 
as would be the case if the index were computed directly on decadal data.

Resulting $\mathrm{SI}_{a}$ and $\overline{\mathrm{SI}}_{\mathrm{a}}$ values were then examined to determine variations in seasonality both on an annual and a decadal basis. Annual seasonality values were also plotted against annual rainfall amounts to determine relationships, if any, between seasonality and rainfall. Further, $\mathrm{SI}_{\mathrm{a}}$ values were plotted and analyzed for trends using the non-parametric Kendall test. Finally, $\overline{\mathrm{SI}}_{\mathrm{a}}$ values were combined for all stations and plotted on a decadal basis to provide an indication of the time evolution of seasonality across the region.

\subsection{Rainfall seasonal trends}

Although both $\mathrm{SI}_{\mathrm{a}}$ and $\overline{\mathrm{SI}}_{\mathrm{a}}$ provide a good indication of rainfall regimes, these indices do not give detailed indications of the distribution of rainfall over the year or of associated amounts and trends, if any, occurring during individual seasons. For example, an $\mathrm{SI}_{\mathrm{a}}$ value of 1.1 (most rain falling in 3 months or less; Walsh \& Lawler 1981) would be obtained regardless of whether the rainfall occurred in consecutive months or at different points during the year, and similarly for years and/or areas with different amounts of rainfall, as long as most of the rainfall occurred in 3 months or less.

To distinguish between wetter and drier periods, long-term monthly medians were first computed for each station and then plotted on a monthly basis. Seasonal distinctions were then made based on a comparison of individual monthly rainfall to the average of the data. Total rainfall was then computed on an annual basis for each season as identified, and then analyzed for trends. Further, data were analyzed for seasonal distribution (\% rain falling in any one season) on both an annual and a long-term basis. Finally, seasonal medians were determined on a decadal basis for each station. These data were then combined and plotted on a decadal basis to provide an indication of the time evolution of seasonal precipitation across the region.

\section{RESULTS}

\subsection{Long-term and decadal trends in annual rainfall}

Fig. 2 shows scatter plots of annual rainfall for the 6 stations along with associated long-term trends. Fig. 3 shows decadal median annual rainfall and trends for the same stations. Based on Fig. 2, a downward trend is visible for Arcadia and Punta Gorda rainfall and upwards trends are visible for all other stations. Based on Fig. 3, downward trends were visible in decadal rainfall at Arcadia, Myakka River, and Punta Gorda, while upward trends were visible at Fort Myers, La Belle, and Naples. For the period for which data for Punta Gorda were available (recent but shorter period), a downward trend was visible at La Belle, and the downward trend observed at Myakka River was more pronounced. Although visible, however, none of the trends were significant on either an annual or a decadal basis based on the trends statistics $(p>0.05)$.

\subsection{Seasonality analysis}

Table 1 shows maximum and minimum individual rainfall seasonality index values for the 6 climate stations in the region while Table 2 shows the seasonality values on a decadal basis. Based on Table 1, the seasons in 1958 were generally equable based on $\mathrm{SI}_{a}$ limits provided in Walsh \& Lawler (1981) $\left(0.20 \leq \mathrm{SI}_{\mathrm{a}} \leq\right.$ $0.39)$, although there remained a definite wetter season. A long drier season was experienced at 3 of the stations in 1974 and at one in 1971. Based on seasonality calculations (Table 1), Myakka River seems to be the only station that experienced a long drier season in recent years. On the decadal time scale, the region experienced a primarily seasonal rainfall regime $\left(0.6 \leq \mathrm{SI}_{\mathrm{a}} \leq 0.79\right.$, based on Walsh \& Lawler 1981), with the exception of Punta Gorda and Fort Myers, which experienced long drier periods in the 2000s and Myakka River, which experienced long drier seasons in the 1940s and short drier seasons in the 1950s.

Fig. 4 shows a comparison of monthly rainfall patterns for years with high (long drier periods) and low (marked wetter periods) seasonality index values with recent (2010) patterns. Periods in which rainfall was more or less equable over the year are visible in the charts as well as those in which there were shorter wetter periods. Seasonality index values were not necessarily related to total annual precipitation (Fig. 5), thus, years with definite wetter seasons or short drier periods are not necessarily ones with the highest amount of rainfall and those with longer drier seasons will not necessarily have the lowest annual rainfall. Correlations ranged from -0.0449 (La Belle) to -0.3593 (Naples), with the only significant relationship being that for Naples $(p=0.0247)$. Other p-values ranged from 0.0616 (Punta Gorda) to 0.8276 (La Belle). 

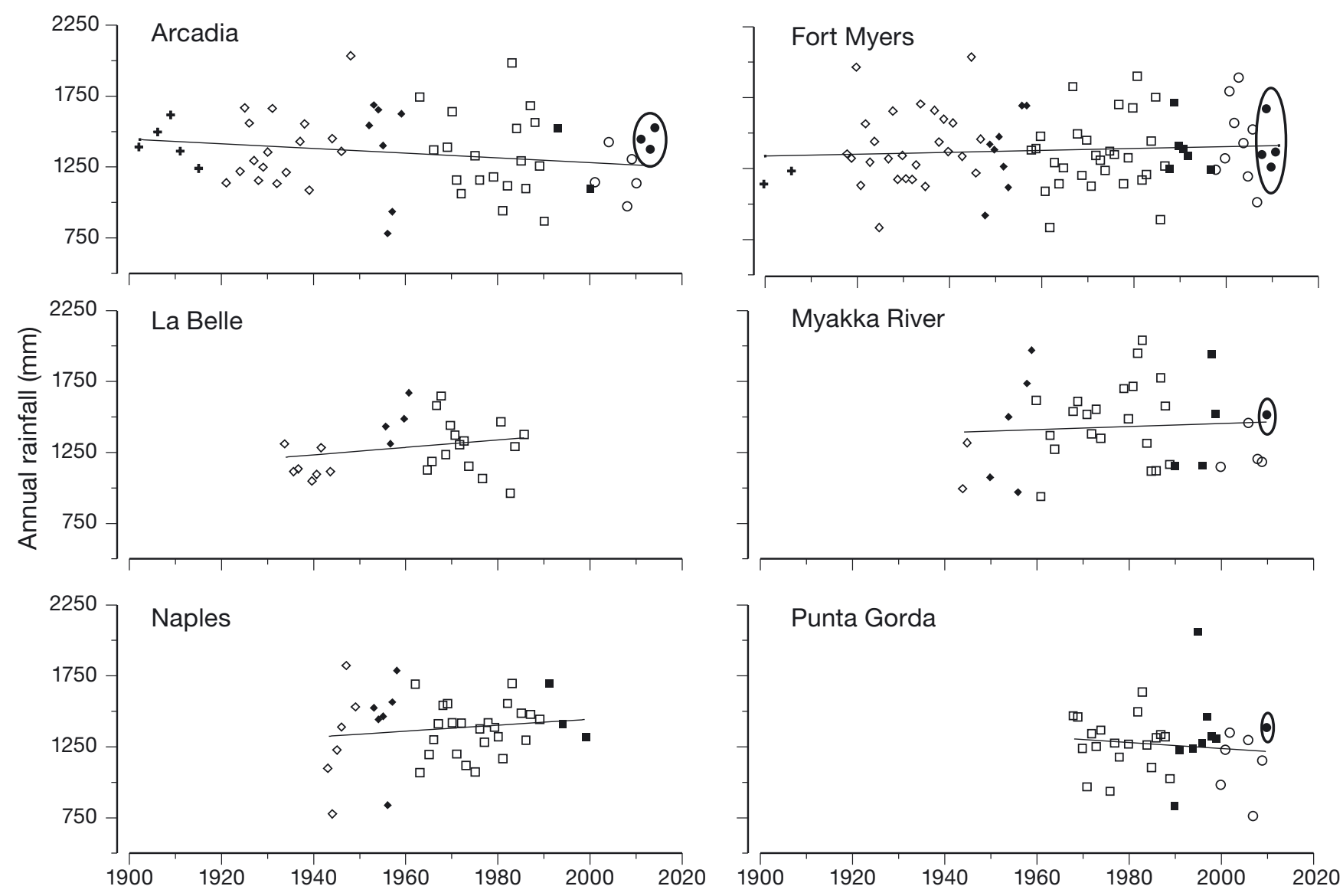

Fig. 2. Trends in annual rainfall for the regional stations. Ellipses show current data (2010-2014) as available for each of the stations. Different markers represent the different decades

Based on Fig. 6, seasonality varied from year to year at all stations. Slight downward trends (tendency towards short drier periods) were observed at Arcadia and Naples, while upward trends (tendency towards long drier periods) were observed at Fort Myers, La Belle, and Punta Gorda. However, none of the trends were significant. A cyclic pattern (marked variations in $\mathrm{SI}_{\mathrm{a}}$ followed by periods with less variation) is, however, observable particularly for stations with longer periods of record (Arcadia, Fort Myers, and Myakka River).

Fig. 7 shows a time evolution of $\overline{\mathrm{SI}}_{\mathrm{a}}$ across the region. A cyclic pattern in $\overline{\mathrm{SI}}_{\mathrm{a}}$ can be observed, with values increasing to a high point and then decreasing to a low point before increasing again. This is not unlike the cyclic patterns generally observed with rainfall over a long period of time. Based on the data shown in Fig. 7, however, there seems to have been a shift in the cyclic periods from $20 \mathrm{yr}$ in the earlier decades up to the 1940s to $30 \mathrm{yr}$ in more recent decades (1950s onwards). Values for the 2010s show a drop from the 2000s $\overline{\mathrm{SI}}_{\mathrm{a}}$ levels, which is expected based on the pattern. However, this (2010s) level is much higher than the previous low (1980s) and is even above the overall mean line $\left(\overline{\mathrm{SI}}_{\mathrm{a}}=0.7\right)$. As only $5 \mathrm{yr}$ of data are available for the current decade at this point, it is possible that the value could become lower when the decade can be considered in its entirety. It is also worthwhile noting that the high value for the 2000s is higher than other high values in past cycles and that the minimum values in these high-value decades (marked with boxes) show progressive increases across cycles from the 1940s. Higher values of $\overline{\mathrm{SI}}_{\mathrm{a}}$ are associated with longer drier seasons, which could indicate a seasonal shift in that direction.

\subsection{Analysis of seasonal rainfall}

Fig. 8 shows long-term median monthly precipitation at the 6 stations in the region. While seasonality is highly variable across years and decades, as observed in prior analyses, when data are aggregated over the 

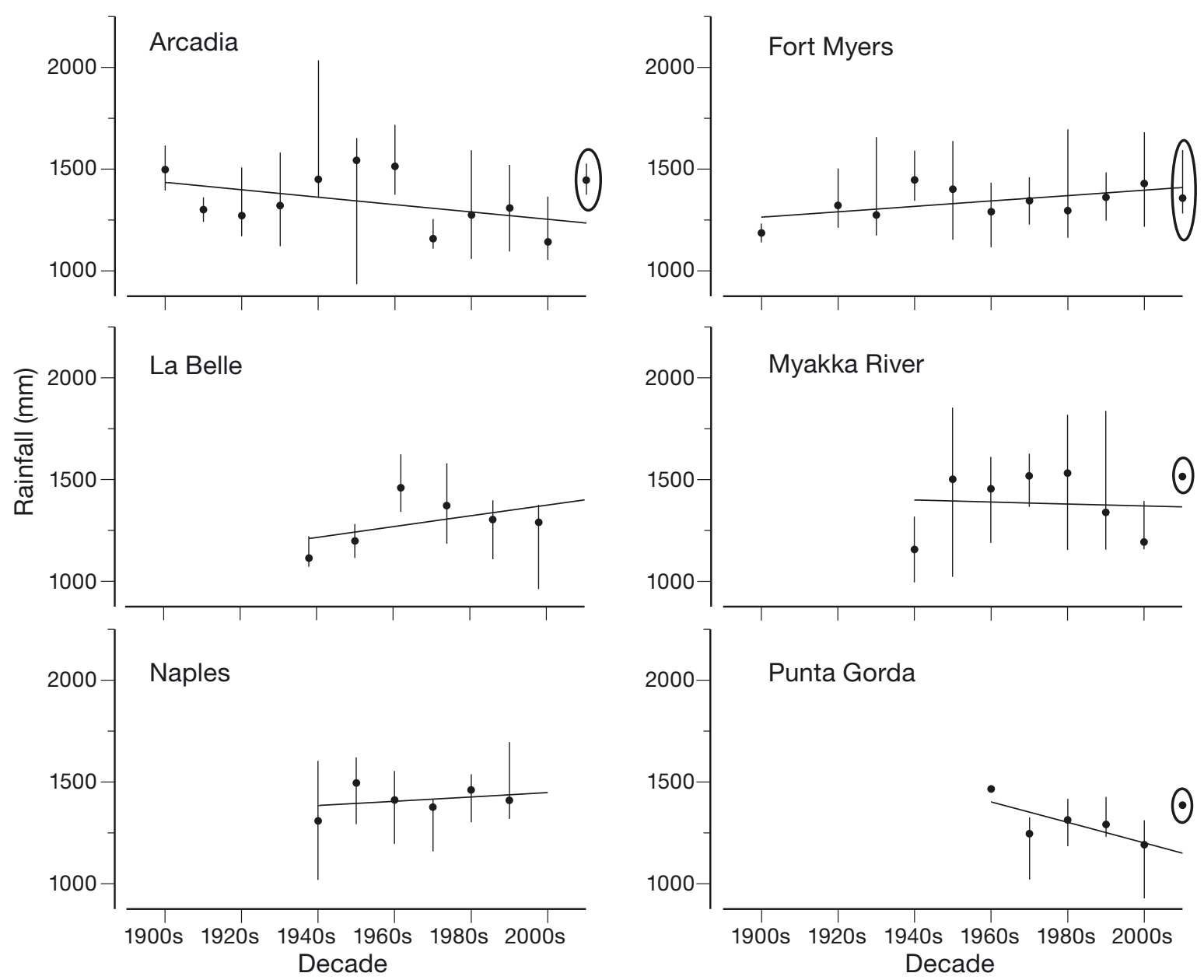

Fig. 3. Trends in decadal median annual rainfall for the regional stations. Error bars: interquartile ranges. Ellipses show current data (2010s) as available for each of the stations

Table 1. Individual seasonality index $\left(\mathrm{SI}_{\mathrm{a}}\right)$ values for the 6 climate stations in the region. Bold: years that were common among the stations with respect to minimum or maximum $\mathrm{SI}_{\mathrm{a}}$

\begin{tabular}{|c|c|c|c|c|}
\hline \multirow[t]{2}{*}{ Station } & \multicolumn{4}{|c|}{$-\mathrm{SI}_{\mathrm{a}}$} \\
\hline & Value (decade) & Interpretation $^{\mathrm{a}}$ & Value (decade) & Interpretation \\
\hline Arcadia & $0.38(\mathbf{1 9 5 8})$ & Equable but with definite wetter season & $0.96(\mathbf{1 9 7 4})$ & Markedly seasonal with long drier season \\
\hline Fort Myers & $0.49(1931,1958)$ & Rather seasonal with short drier season & $1.10(\mathbf{1 9 7 4})$ & Most rain in $\leq 3$ mo \\
\hline LaBelle & $0.38(\mathbf{1 9 5 8})$ & Equable but with definite wetter season & $0.90(1981) \quad \mathrm{I}$ & Markedly seasonal with long drier season \\
\hline Myakka River & $0.33(\mathbf{1 9 5 8})$ & Equable but with definite wetter season & $0.97(2006) \quad \mathrm{I}$ & Markedly seasonal with long drier season \\
\hline Naples & $0.44(1983)$ & Rather seasonal with short drier season & $0.99(1971)$ & Markedly seasonal with long drier season \\
\hline Punta Gorda & $0.45(1983)$ & Rather seasonal with short drier season & $1.06(\mathbf{1 9 7 4})$ & Most rain in $\leq 3$ mo \\
\hline
\end{tabular}

long term, a distinct wetter period (June-September) and drier periods (January-May and OctoberDecember) are observable. This is consistent with information from the Charlotte Harbor National Estuary Program (2010) and Obeysekera et al. (1999), both documenting a wetter period running from June to
September and a drier period lasting from October of one year through May of the following year. For the present analysis, this drier period is split into 2 periods (January-May and October-December) with the wetter period in between, consistent with Fig. 8. While these distinctions provide a generalized picture of the 
Table 2. Decadal seasonality index $\left(\overline{\mathrm{SI}}_{\mathrm{a}}\right)$ values for the 6 climate stations in the region

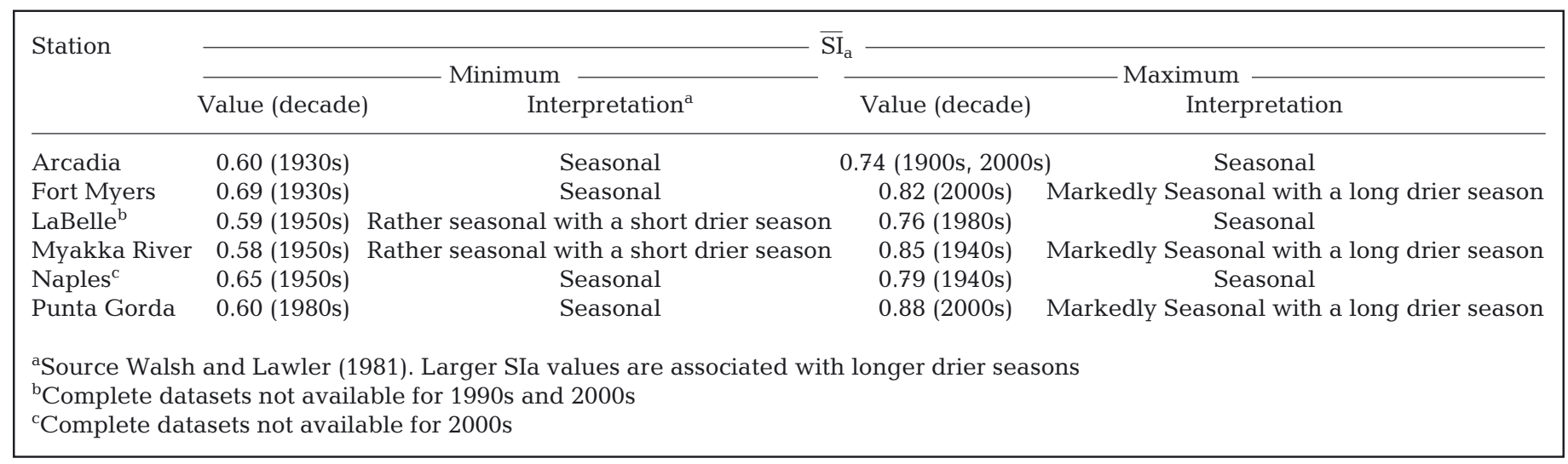
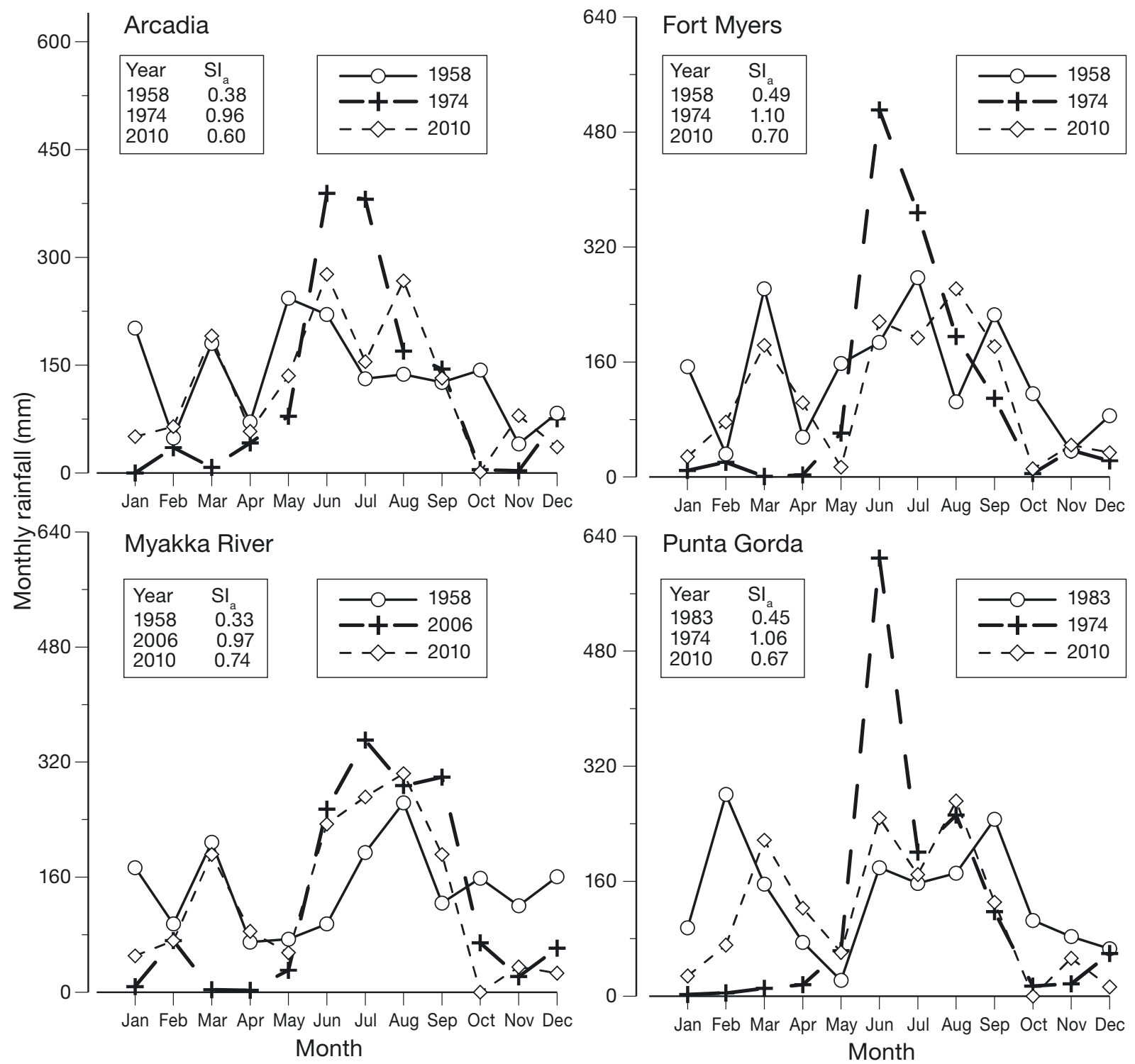

Fig. 4. Monthly rainfall at selected stations for years with high (long drier periods) and low (marked wetter periods) individual seasonality index $\left(\mathrm{SI}_{\mathrm{a}}\right)$ values in comparison to a recent year (2010) 

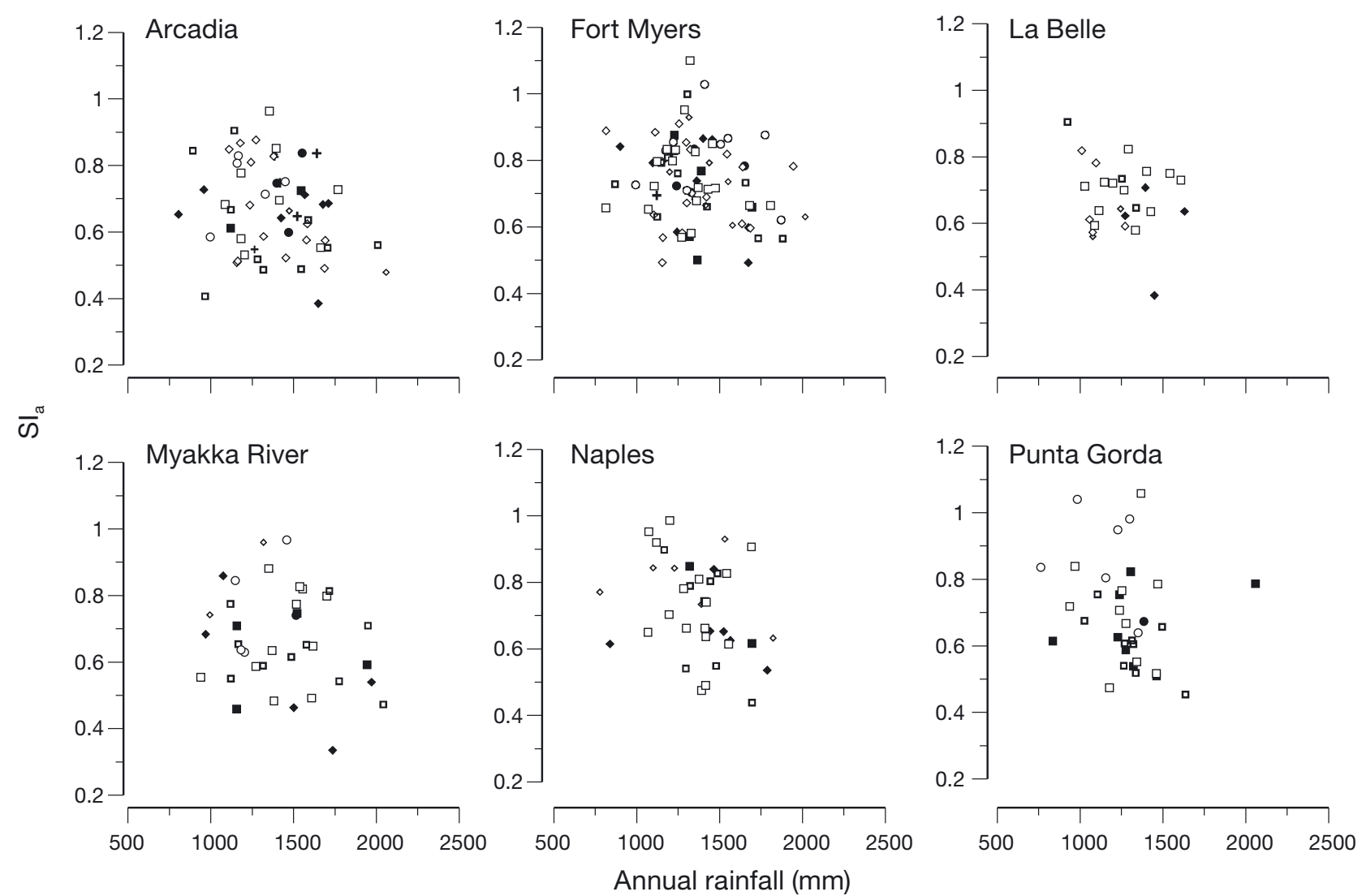

Fig. 5. Relationship between annual seasonality index $\left(\mathrm{SI}_{\mathrm{a}}\right)$ and annual rainfall for regional stations. Different markers represent the different decades

rainfall regime, based on the previous analyses, they provide a basis for separating data for seasonal analyses. For the present study, seasonal designations were assigned as follows: January-May: Dry 1; OctoberDecember: Dry 2; and June-September: Rainy. While variations in seasonal precipitation were observed at the various stations across the years (Fig. 9), trends were generally not significant, with the exception of increases in rainy season rainfall amounts at Fort Myers, which were significant on both an annual and a decadal basis ( $p=0.0207$ and $p=0.0286$, respectively). Over the long term, rainfall distribution was more or less the same for all stations, with approximately $63 \%$ of rainfall falling in Rainy and 24 and $13 \%$ falling in Dry 1 and Dry 2, respectively. The region generally had a substantially higher amount of rainfall (compared to the long-term average) falling during the rainy season (>80\%) in both 1974 and 2006. These are also the years that showed longer drier seasons based on seasonality analyses (Table 1). These years also generally had the lowest amount of rainfall experienced across the stations for the years considered, with annual rainfall being at about the climate normal. This is with the exception of Punta Gorda, for which annual rainfall (1298 $\mathrm{mm})$ was below normal. For 2010, the amount of rainfall falling during Rainy was consistent with the long-term average. However, substantially more rainfall $(>30 \%)$ fell in Dry 1 than what generally occurs in the region based on longterm distributions, while the percentage occurring in Dry 2 was similar to percentages in 1974 and 2006. The rainfall occurring in 2010 generally corresponded to regional normals (1320-1420 mm) except at Myakka River, for which the annual rainfall was substantially higher. Rainfall amounts were also substantially higher than regional normal in 1983, especially at Fort Myers and Myakka River.

Fig. 10 shows the time evolution of seasonal rainfall for stations in the region. Based on this figure, rainfall occurring across the region in Dry 1 (January-May) showed variations but did not change substantially across the decades, with the exception of the 2000s, for which a marked decrease was observed. However, rainfall falling in Dry 2 (October-December) showed a progressive decline from about the 1950s to the present decade, while Rainy (June-September) rainfall showed higher levels from the 1990s through the current decade. 

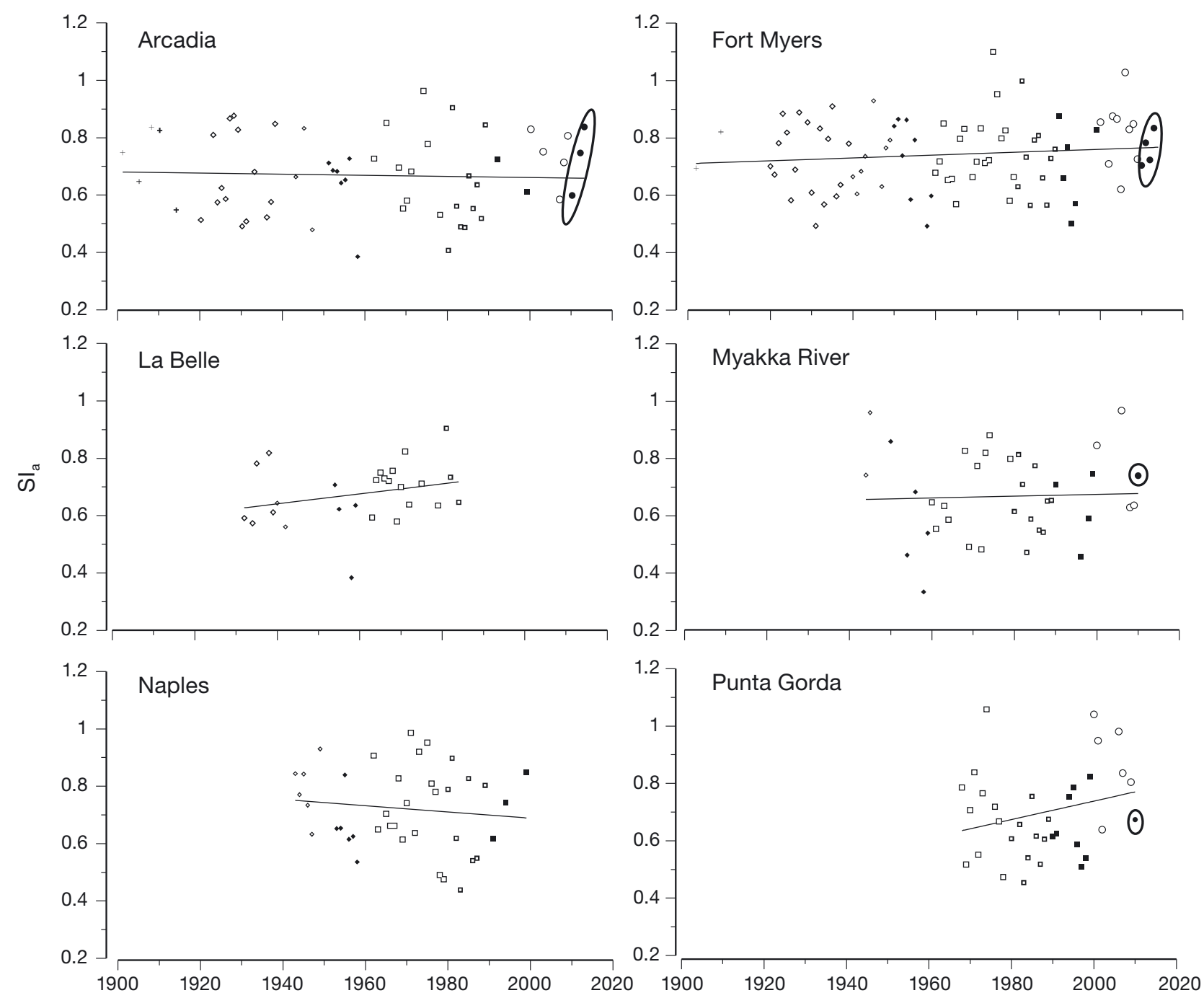

Fig. 6. Trends in annual seasonality index $\left(\mathrm{SI}_{\mathrm{a}}\right)$ for the regional stations. Ellipses show current data (2010-2014) as available for each of the stations. Different markers represent the different decades

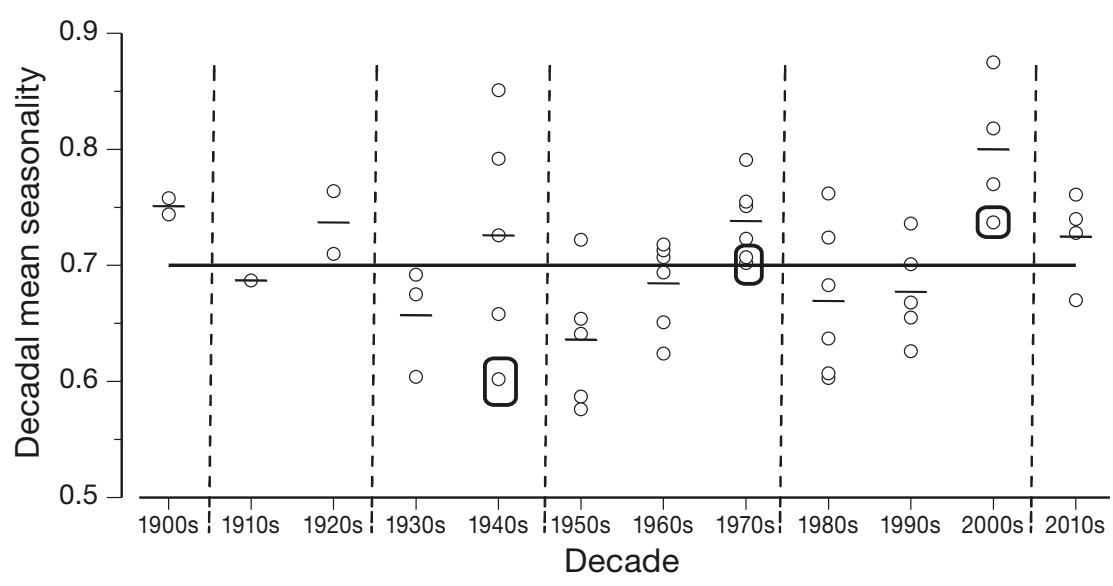

Fig. 7. Time evolution of $\overline{\mathrm{SI}}_{\mathrm{a}}$ showing decadal variations across the region. Short horizontal lines: averages for the respective decades. Solid line represents the mean of the data. Dotted vertical lines demarcate periods in which mean seasonality increases progressively from a low point to a high point before dropping back to a low point. Rounded rectangles highlight evolution of lowest values for decades in which highest means occur

\section{DISCUSSION}

\subsection{Seasonal variability and change}

Based on the analyses, the region experiences marked variations in rainfall, seasonality, and seasonal rainfall. Within the region, the amount of rainfall falling during a year is affected by climate phenomena such as the El Niño-Southern Oscillation (ENSO), which primarily affects winter rainfall (NOAA 2015), and the Atlantic Multidecadal Oscillation, which affects total rainfall amounts and the occurrence of hurricanes (NOAA 2005). Winters in the region are generally cool and wet during El Niño years and warm and 


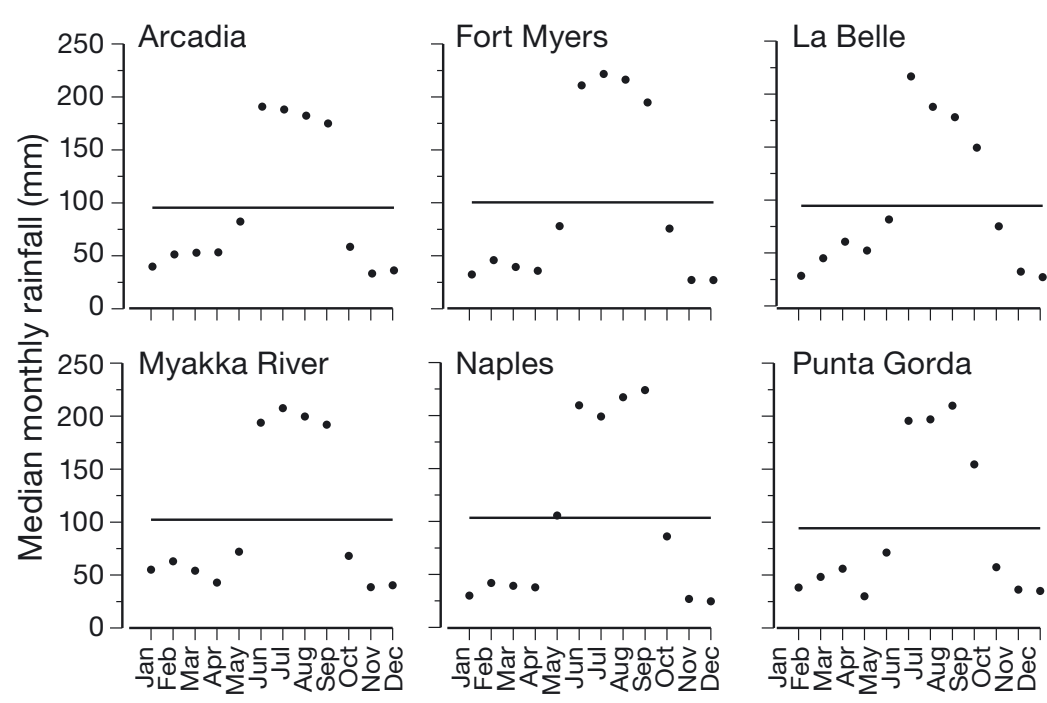

Fig. 8. Long-term median monthly precipitation at the 6 stations in the region. Solid lines: mean of the data

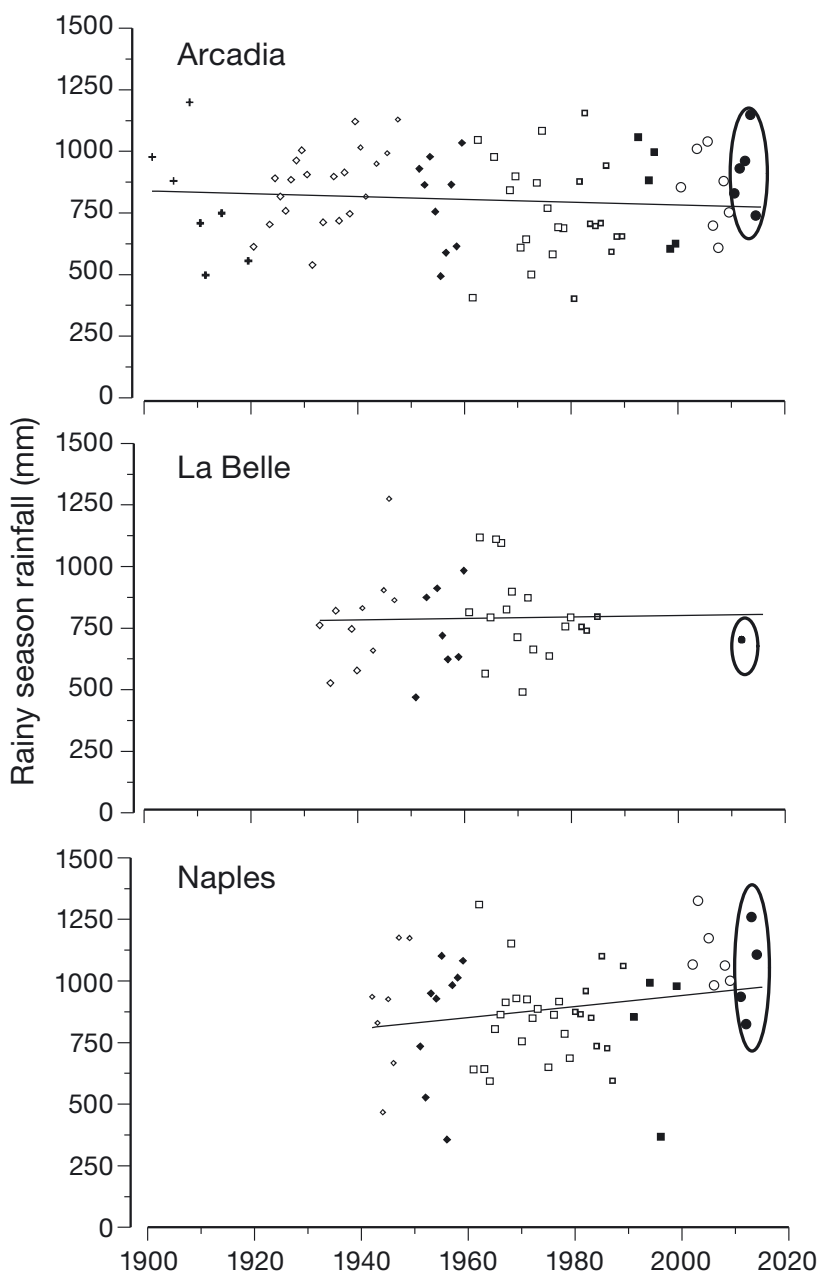

dry during La Niña conditions. More rainfall is experienced in the region when the Atlantic is in its warm cycle. Warm cycles were experienced in 1860-1880 and 1940-1960, while cool cycles were experienced in 1905-1925 and 1970-1990 (Enfield et al. 2001). The ocean was in a warm cycle in 2005 based on NOAA data (NOAA 2005). Similarly, effects on rainfall amounts and seasonality are noted by Poveda et al. (2001) due to ENSO, and by Luo and Zhang (2015) and Arias et al. (2012) due to different climate modulators. These phenomena can also experience shifts, thereby also impacting seasonality (e.g. Luo \& Zhang 2015). Thus, there is the need to determine the extent to which these phenomena, and any associated shifts, impact seasonal-
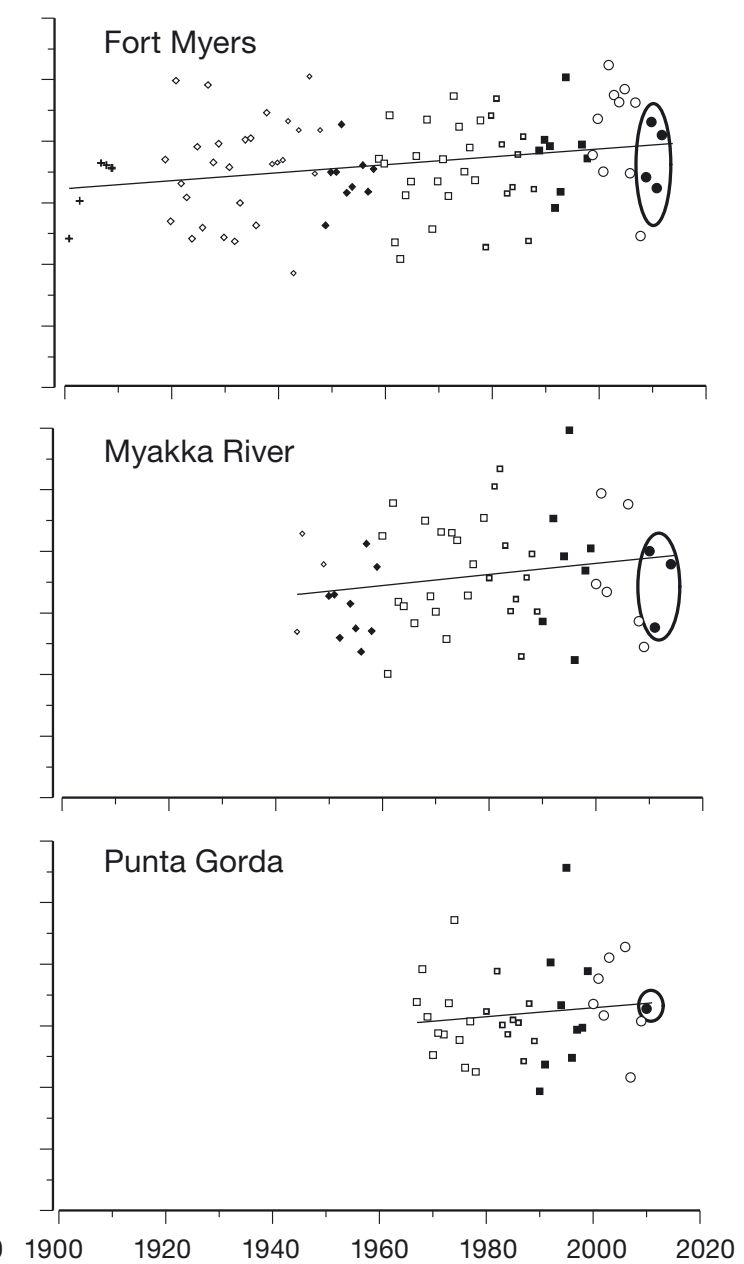

Fig. 9. Trends in rainy season rainfall at region stations. Ellipses show current data (2010-2014) as available for each of the stations. Different markers represent the different decades 

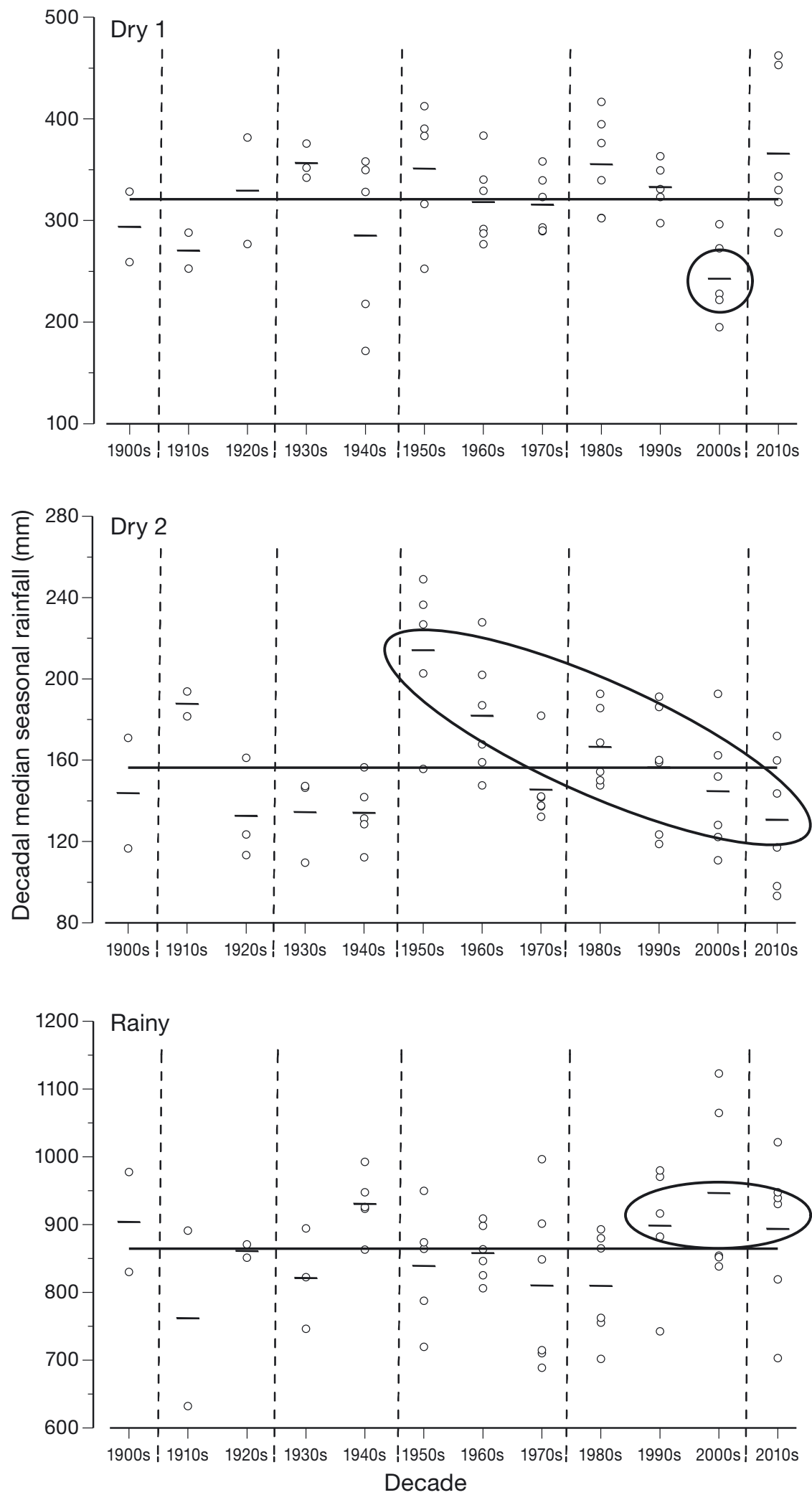

Fig. 10. Time evolution of seasonal rainfall showing decadal variations across the region. Ellipses: occurrences and patterns that warrant attention. See Section 3.3. Short horizontal lines: averages for the respective decades. Solid line: mean of the data ity in the region. However, such analysis is beyond the scope of this study.

From the analyses, significant trends were not observed in long-term annual rainfall when data were considered on either an annual or a decadal basis. This was consistent with observations by Charlotte Harbor National Estuary Program (2010), although these authors observed statistical significance when data were considered on a moving (10 yr) average basis. The lack of statistically significant trends in annual rainfall amounts could, in part, reflect the effects of the cyclic climate phenomena, as also noted by Pal et al. (2013). However, lack of statistical significance at the annual level does not necessarily imply a static rainfall regime, as variabilities occurring within the year could change over time (for example, as documented by Pryor \& Schoof 2008). In the present study, analyses showed variations in seasonality with a tendency towards long drier periods. Variations were also observed in rainfall distribution, with rainfall being distributed more or less evenly in some of the years and occurring primarily during the rainy periods in others. Further, variations were observed in seasonal rainfall, with increases in rainy season rainfall and progressive decreases in one of the dry periods. This is consistent with conservative climate predictions for the region (wetter wet seasons and drier dry seasons; Charlotte Harbor National Estuary Program 2010). Thus an evaluation of only the annual rainfall data would lead to the erroneous conclusion that climate was unchanging in the region.

Changes in rainfall occurrence, amounts, and distribution have immediate and pertinent implications on water resources management in the region, for example, on cycles of water releases and retention in Lake Okeechobee (Enfield et al. 2001), which, in turn, affect freshwater and saltwater influxes in the estuarine region and ultimately impact ecosystem integrity in the region. Long drier periods accompanied by decreases in dry 
period rainfall constitute drought conditions, thus also posing water management challenges in the region including providing water for agriculture and ensuring adequate supplies for rapidly growing urban populations. Drought conditions also bring about increased risk of wildfire damage and dry-outs of coastal wetlands, which can make it more difficult to adapt to other climate change effects such as sea level rise. Increase in rainy season precipitation also presents challenges, including the need for flood control while also considering the need to protect estuarine areas from excessive freshwater influxes. Fraser (1997) observed that species diversity was impacted by freshwater inflows, with richer diversity being attributed to lower inflows and associated higher salinity but less so during wetter periods.

Among the climate change predictions for the study region are the occurrence of more variable rainfall with longer dry spells and increases in hurricane severity (Stanton \& Ackerman 2007). An overall decrease in hurricane and tropical storm activity is also predicted (Bender et al. 2010, Christensen et al. 2013), although increases are predicted in the frequencies of category 4 and 5 hurricanes (Bender et al. 2010) and the nature of anticipated changes in extreme events remains uncertain (Christensen et al. 2013). The tendency towards long drier spells and decreasing rainfall in one of the drier periods is seen in this study. However, changes in seasonality associated with extreme events are difficult to discern from this analysis. None of the maximum or minimum $\mathrm{SI}_{\mathrm{a}}$ values were associated with years in which the region was impacted by major hurricanes. Rust et al. (2009) proposed a method of evaluating seasonality in relation to extreme events based on a seasonally varying generalized extreme value model, while Dhakal et al. (2015) used non-parametric approaches to assess temporal changes in the same. Similar analyses would provide insights into changes, if any, occurring in extreme events and their associated seasonality in the study region.

\subsection{Seasonality analysis}

The seasonality index does not generally account for temporal distribution of rainfall or rainfall amounts, although this can be discerned for $\mathrm{SI}_{\mathrm{a}}$ values of zero or near zero, which indicate that rainfall is distributed equally across all months of the year (Walsh \& Lawler 1981, Sumner et al. 2001). For all other values, however, an in-depth look at the monthly rainfall is needed to obtain a perspective on when and how much rainfall occurs during the year. An alternative would be to use principal component analysis to study the distribution of rainfall in each year, as well as associated changes and possible trends. This methodology would require datasets without missing values, but could also employ a regional dataset developed by aggregating normalized data from the different regional stations.

The seasonality index, however, has value in that it provides an overall picture of rainfall variability that is easy to compute and understand, and that can be used to assess changes in rainfall regimes over time and across regions. Guhathakurta \& Saji (2013) and Sumner et al. (2001), for example, both found increases in seasonality (tendency towards long drier periods) in their respective study regions as well as differences in rainfall regimes across the regions.

A completely equable distribution would mean that each month contributes $8.33 \%$ of the total annual rainfall. For the study region, this would translate to $42 \%$ of the rainfall occurring in Dry 1, 25\% occurring in Dry 2, and $33 \%$ occurring in Rainy 1 . This scenario is seen in an approximate sense in 1958 at Myakka River but is otherwise not typical of the region. The relative contribution of each month to $\mathrm{SI}_{\mathrm{a}}$ can be determined as detailed in Sumner et al. (2001), allowing the evaluation of changes in the significance of contributions from any given month. An analysis of daily values would provide insights on within-season variations and also provide a means of getting around the lack of trend resulting from the impacts of natural phenomena.

\section{CONCLUSIONS}

This study determined long-term seasonality of rainfall in the coastal zone with particular focus on the southwest Florida Gulf coastal zone. Based on the analyses, the region experiences marked variations in annual rainfall as well as in seasonality and associated seasonal rainfall. On a regional basis, the analyses showed a tendency towards long drier periods along with increases in rainy season (June-September) rainfall and progressive decreases in seasonal rainfall in one of the dry periods (October-December). Changes in rainfall occurrence, amounts, and distribution have immediate and pertinent implications for water resource management in the region. Thus, results provide information that is useful for management decision-making while also providing a basis for further assessments in the region. Approaches and methodologies are applicable to other coastal areas. 
Acknowledgements. Many thanks to Sara Raissa Brito Bezerra for her work in organizing and preprocessing the climate data.

\section{LITERATURE CITED}

Arias P, Fu R, Mo K (2012) Decadal variation of rainfall seasonality in the North American monsoon region and its potential causes. J Clim 25:4258-4274

Bender MA, Knutson TR, Tuleya RE, Sirutis JJ, Vecchi GA, Garner ST, Held IM (2010) Modeled impact of anthropogenic warming on the frequency of intense Atlantic hurricanes. Science 327:454-458

> Berghuijs W, Sivapalan M, Woods R, Savenije H (2014) Patterns of similarity of seasonal water balances: a window into streamflow variability over a range of time scales. Water Resour Res 50:5638-5661

Celleri R, Willems P, Buytaert W, Feyen J (2007) Space-time rainfall variability in the Paute Basin, Ecuadorian Andes. Hydrol Processes 21:3316-3327

Charlotte Harbor National Estuary Program (2010) Charlotte Harbor regional climate change vulnerability assessment. Available at www.chnep.org/GrantsReceived/CRE/Vulner abilityAssessment2-19-10.pdf (accessed 12/17/2015)

Christensen JH, Krishna Kumar K, Aldrian E, An SI and others (2013) Climate phenomena and their relevance for future regional climate change. In: Stocker TF, Qin D, Plattner G-K, Tignor M and others (eds) Climate change 2013: the physical science basis. Contribution of Working Group I to the Fifth Assessment Report of the Intergovernmental Panel on Climate Change. Cambridge University Press, Cambridge

Coopersmith E, Yaeger M, Ye S, Cheng L, Sivapalan M (2012) Exploring the physical controls of regional patterns of flow duration curves. 3. A catchment classification system based on regime curve indicators. Hydrol Earth Syst Sci 16:4467-4482

Dhakal N, Jain S, Gray A, Dandy M, Stancioff E (2015) Nonstationarity in seasonality of extreme precipitation: a nonparametric circular statistical approach and its application. Water Resour Res 51:4499-4515

Enfield D, Mestas-Nunez A, Trimble P (2001) The Atlantic multidecadal oscillation and its relation to rainfall and river flows in the continental US. Geophys Res Lett 28: 2077-2080

Feng X, Porporato A, Rodriguez-Iturbe I (2013) Changes in rainfall seasonality in the tropics. Nat Clim Change 3: $811-815$

Fraser TH (1997) Abundance, seasonality, community indices, trends and relationships with physicochemical factors of trawled fish in upper Charlotte Harbor, Florida. Bull Mar Sci 60:739-763

Gill A (2005) Offshore renewable energy: ecological implications of generating electricity in the coastal zone. J Appl Ecol 42:605-615

Guhathakurta P, Saji E (2013) Detecting changes in rainfall pattern and seasonality index vis-a-vis increasing water scarcity in Maharashtra. J Earth Syst Sci 122:639-649

Hu Z, Yang S, Wu R (2003) Long-term climate variations in China and global warming signals. J Geophys Res D Atmos 108:4614

Kanellopoulou EA (2002) Spatial distribution of rainfall seasonality in Greece. Weather 57:215-219

Lana X, Martinez M, Serra C, Burgueno A (2004) Spatial and temporal variability of the daily rainfall regime in Catalonia (northeastern Spain), 1950-2000. Int J Climatol 24:613-641
Livada I, Asimakopoulos DN (2005) Individual seasonality index of rainfall regimes in Greece. Clim Res 28:155-161

Luo X, Zhang Y (2015) Interdecadal change in the seasonality of rainfall variation in South China. Theor Appl Climatol 119:1-11

NOAA (National Oceanic and Atmospheric Administration) (2005) Frequently asked questions about the Atlantic Multidecadal Oscillation. www.aoml.noaa.gov/phod/amo_ faq.php (accessed 12/10/2015). NOAA, Silver Spring, MD

NOAA (National Oceanic and Atmospheric Administration) (2015) South Florida climate page. www.srh.noaa.gov/mfl/ ?n=winteroutlookforsouthflorida (accessed 12/10/2015). NOAA, Silver Spring, MD

NOAA (National Oceanic and Atmospheric Administration) (undated) Hurricanes in history. NOAA, Silver Spring, MD. https://nhc.noaa.gov/outreach/history/\#top (accessed 12/17/2015)

Obeysekera J, Browder J, Hornung L, Harwell MA (1999) The natural South Florida system. I. Climate, geology, and hydrology. Urban Ecosyst 3:223-244

Pal I, Anderson B, Salvucci G, Gianotti D (2013) Shifting seasonality and increasing frequency of precipitation in wet and dry seasons across the US. Geophys Res Lett 40: 4030-4035

> Poveda G, Jaramillo A, Gil M, Quiceno N, Mantilla R (2001) Seasonality in ENSO-related precipitation, river discharges, soil moisture, and vegetation index in Colombia. Water Resour Res 37:2169-2178

> Pryor S, Schoof J (2008) Changes in the seasonality of precipitation over the contiguous USA. J Geophys Res D Atmos 113:D21108, doi:10.1029/2008JD010251

Rust H, Maraun D, Osborn T (2009) Modelling seasonality in extreme precipitation. Eur Phys J Spec Top 174:99-111

Stanton EA, Ackerman F (2007) Florida and climate change: the costs of inaction. Tufts University, Global Development and Environment Institute and Stockholm Environment Institute-US Center

Sumner G, Homar V, Ramis C (2001) Precipitation seasonality in eastern and southern coastal Spain. Int J Climatol 21:219-247

> Tedesco PA, Hugueny B, Oberdorff T, Durr HH, Merigoux S, de Merona B (2008) River hydrological seasonality influences life history strategies of tropical riverine fishes. Oecologia 156:691-702

US Commission on Ocean Policy (2004) An ocean blueprint for the 21st century. Final Report. US Commission on Ocean Policy, Washington, DC. http://govinfo.library.unt.edu/ oceancommission/documents/full_color_rpt/000_ocean_ full_report.pdf

US Environmental Protection Agency (2012) National Coastal Condition Report IV. US EPA, Washington, DC

> Walsh P, Lawler D (1981) Rainfall seasonality: description, spatial patterns and change through time. Weather 36 : 201-208

Wilson MA, Farber S (undated) Accounting for ecosystem goods and services in coastal estuaries. In: Pendleton LH (ed) The economic and market value of coasts and estuaries: What's at stake? Restore America's Estuaries, Arlington, VA, p 14-36. www.habitat.noaa.gov/pdf/economic and_market_valueofcoasts_and_estuaries.pdf (accessed June 2016)

Wong PP, Losada IJ, Gattuso JP, Hinkel J and others (2014) Climate change 2014: impacts, adaptation, and vulnerability. Part A. Global and sectoral aspects. Contribution of Working Group II to the Fifth Assessment Report of the Intergovernmental Panel on Climate Change. Cambridge University Press, Cambridge 